\title{
和歌山地方の地殼構造について
}

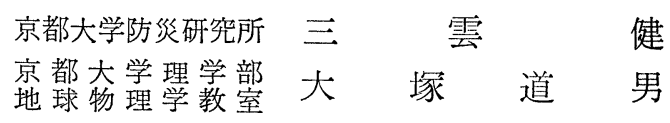

(昭和 35 年 7 月 18 日受理)

\section{Seismic Studies on the Crustal Structure in Wakayama District}

\author{
Takeshi Miкumo \\ Disaster Prevention Research Institute, Kyoto University \\ Michio ŌTsuKa \\ Geophysical Institute, Faculty of Science, Kyoto University
}

(Received July 18, 1960)

The crustal structure in Wakayama District was derived from close observations of local and near earthquakes at network stations spread over the area. Laboratory experiment on bed rocks was also made to get reference data on seismic velocities.

The propagation velocities of the $P$ - and $S$-waves and the layer thickness obtained, are: $V_{p}=4.3 \mathrm{~km} / \mathrm{sec}, V_{s}=2.4 \mathrm{~km} / \mathrm{sec}, h_{1}=4 \mathrm{~km}$ for the sedimentary layer, $V_{p}=5.5 \mathrm{~km} / \mathrm{sec}, V_{s}$ $=3.2 \mathrm{~km} / \mathrm{sec}, h_{2}=7 \mathrm{~km}$ for the granitic layer, $V_{p}=6.1 \mathrm{~km} / \mathrm{sec}, V_{s}=3.5 \mathrm{~km} / \mathrm{sec}, h_{3}=15 \mathrm{~km}$ for the basaltic layer, and $V_{p}=8.0 \mathrm{~km} / \mathrm{sec}, V_{s}=4.5 \mathrm{~km} / \mathrm{sec}$ for the mantle surface, respectively. The crustal depth to the Mohorovicić discontinuity in this region is estimated to be about $26 \mathrm{~km}$.

The spatial distribution of foci of micro-earthquakes in the northern part of the district, is confined above the granitic layer.

\section{$\S 1$. 序 言}

地震波による地殼構造の研究は，今世紀に入つて以来多くの地震学者によつて種々の立場か ら行なわれてきたが，近年観測精度の向上に伴なつて，地殼構造の詳細な地域性や，これと地 震発生の状態との関連なども研究されるょうになつた，この方法としては，人工爆破による他， 局地地震や近地地震を高い精度で観測することも一つの有力な手段と考学られる.

よく知られているょうに，和歌山地方では古来局地地震が頻発しているが，われわれは，こ れら微小地震の性状とこの地方の地殼構造を詳細に調査する目的で, 東京大学地震研究所と協 力し, 高感度電磁地震計を備えた多数の観測点をこの地域に設置して, 数年来, これら地震の 精密観測を行なつてきた。観測の方法特よび結果の一部はすでに報告された通りである ${ }^{12,2), 31}$.

この論文に特いては，1954，1956 执よび 1959 年の 3 回にわたる観測結果を綜合して。この 地域の地殼構造の推定を試みた。推定の基礎となつた data は，この観測網で観測されたもの 
のうち, 震源が決定された 36 個の局地地震と, 高い精度で記録された 9 個の近地地震である. な执，参考のために，この地方の表層の岩石資料について室内実験を行なつた。

\section{§2. 局地地震観測から推定される地殼の上部構造}

Fig. 1 は 1954，1956，1959 年の 3 回の観測に搞ける各観測点の位置およびこれらの観測で 決められた 36 個の局地地震の震央を示す. 前 2 回の観測結果は前報 ${ }^{2)}$ に報告したが，上図拉 よび以下の議論には 1959 年の結果 ${ }^{4)}$ を含んでいる.

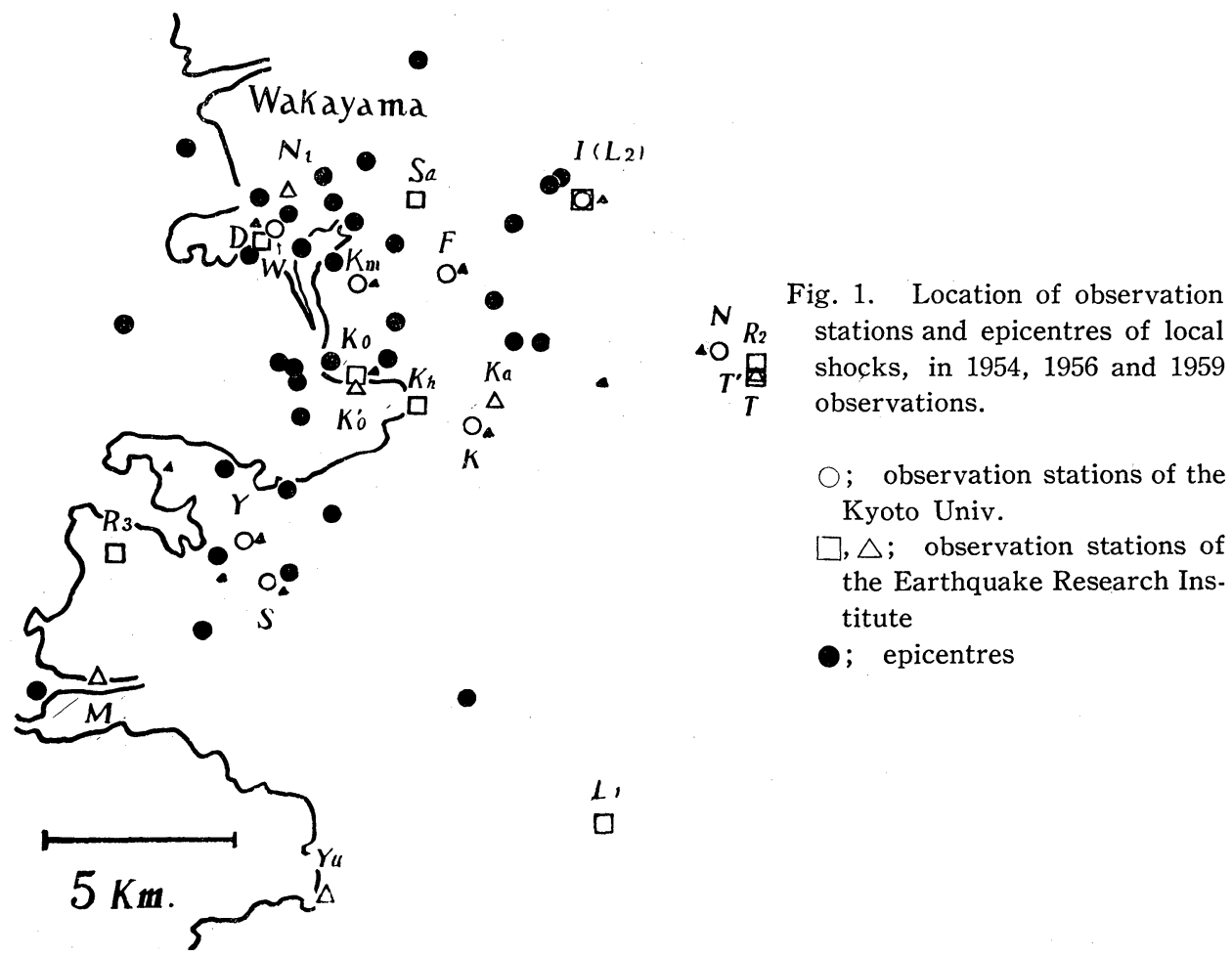

これらの震源は，第 1 近似としてこの地域の構造を uniform medium と仮定し，各観測点 に和仔る $P$ 波の到着時間または $P \sim S$ 時間によつて決定したものである.

次にこれらの震源の深さと， $P$ 波， $S$ 波の速度 $V_{p}, V_{s}$ 特よび距離係数 $k$ との関係を Fig. 2 に示す・ただしこれらの量はいずれる上の仮定の下゙に訃算された值であつて，必らずしも実際 のものとは考吕ない。

次に示された関係を見ると，深さ $4 \mathrm{~km}$ 以下の地震については速度はほぼ一定とみなされ， 縱波について約 $4.3 \mathrm{~km} / \mathrm{sec}$, 横波に対して約 $2.4 \mathrm{~km} / \mathrm{sec}$ の值を取る.この結果と，深さ $0 \mathrm{~km}$ にプロットされた下津附近に扮ける地震探査 ${ }^{5)}$ の結果を考慮すれば，このような伝播速度を有 する表層が約 $4 \mathrm{~km}$ の深さまで存在すると考觉られる. 


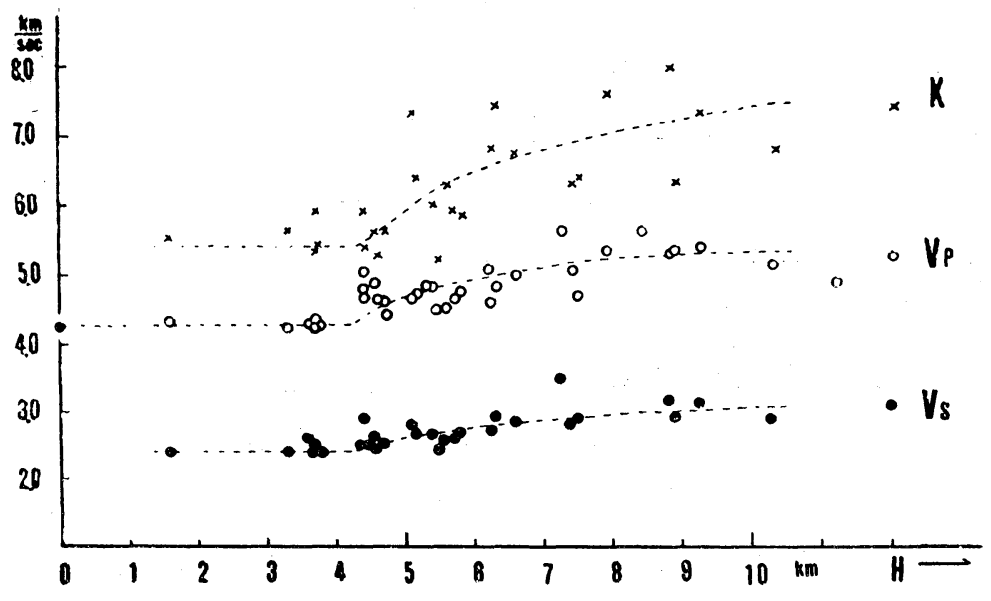

Fig. 2. Wave velocity versus focal depth.

震源の深さ $4 \mathrm{~km}$ 超光る地震に対しては, 伝播速度は深さとともに增大する傾向が見られ る. このことは，この地方の地殼の上部構造が一様ではなく，下部ほど速度が増大しているこ とを示すものである. いま，第 2 近似として水平成層構造を仮定し，Fig. 2 に示された分布に 適合するように第 2 層中の速度を決めれば， $P$ 波速度約 $5.5 \mathrm{~km} / \mathrm{sec}, S$ 波速度約 $3.2 \mathrm{~km} / \mathrm{sec}$ が得られる．この決定法については前報2)で述べたので省略する.

\section{§3. 超音波による表層岩石中の弾性波速度の測定}

表層中を通過する地震波の伝播速度について一つの参考資料を得る目的で，この地方の 12 個所, 特に地震観測点附近に执いて, 露頭岩盤から 32 個の岩石資料を蒐集し, これら岩石中 の弾性波速度を超音波法によつて測定した。こ れらの岩石は緑泥片岩, 石墨千枚岩, 石英片岩 などの变成岩である。資料を採集した場所は Fig. 1 に示した.

測定は京大阿武山地震観測所で行なつた。測 定装置抏よび方法は先に報告されている通りで ある 音波 $(500 \mathrm{KC})$ の発生には $X$-cut の $\mathrm{BaTiO}_{3}$ の crystal を使用した.

得られた速度は資料によりかなり異なり，大 部分は 4〜 $6 \mathrm{~km} / \mathrm{sec}$ の值を示すが，資料の蒐集 場所による差異は明瞭でない. Fig. 3 は各資

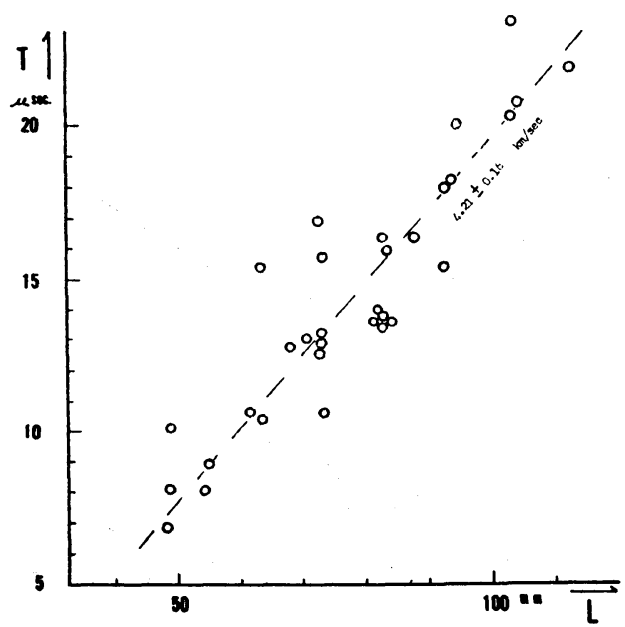

Fig. 3. Ultrasonic transmission times against the length of rock specimens. 
料の長さに対する弾性波の伝播時間を示したものである.特にはずれの大きい 3 個を除いた 29 個の資料に対して最小自乗法を適用すると， $V_{p}=4.21 \pm 0.16 \mathrm{~km} / \mathrm{sec}$ なる見掛けの速度が得 られる. 個々の岩石中の速度と，この全資料に対する見掛けの速度の差が何に起因するかは明 らかでない,ここでは, 後者が前節に述べた局地地震技よび地震探査から得られた表層中の速 度とかなり良く一致することを附け加えるに止める。

\section{§4. 近地地震観測から推定される地殼の下部構造}

地殼下部の構造を推定するためには, 普通, 震央附近の観測網以外に比較的遠距離の観測点 が必要である.われわれはここでは，この地域に設置した局地地震の観測網を利用し，高い時 刻精度で，この地域外に起つた近地地震を観測する方法を採つた. 1956 年および 1959 年の観 測期間中に, $P \sim S$ 時 6 秒以上の近地地震 9 個が 3 観測点以上で記録された.

（1）伝播速度の決定

a) 走時曲線による方法 以上のうち 4 個の地震については, 各測候所の観測資料により 震源を決定することができた. Fig. 4 (a)〜 (d) はこれらの地震の走時曲線を示す.われわれの

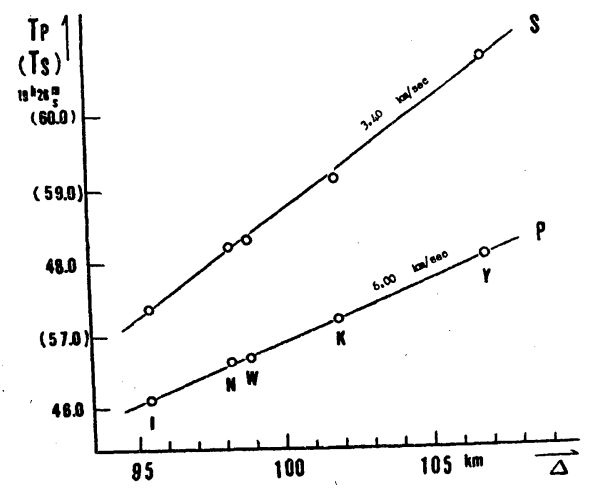

(a) No. 240

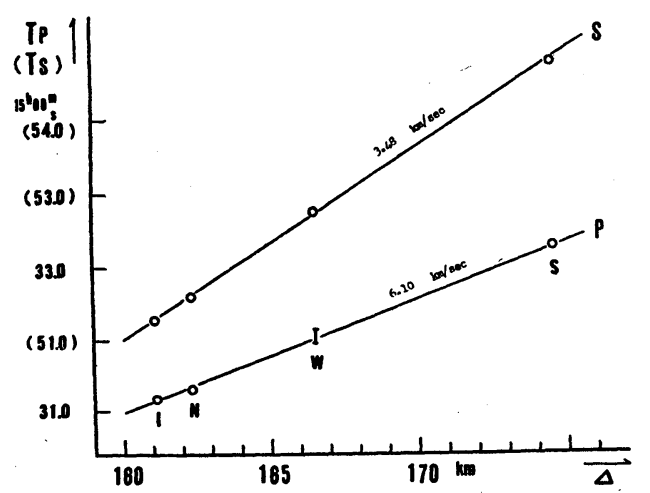

(c) No. 371

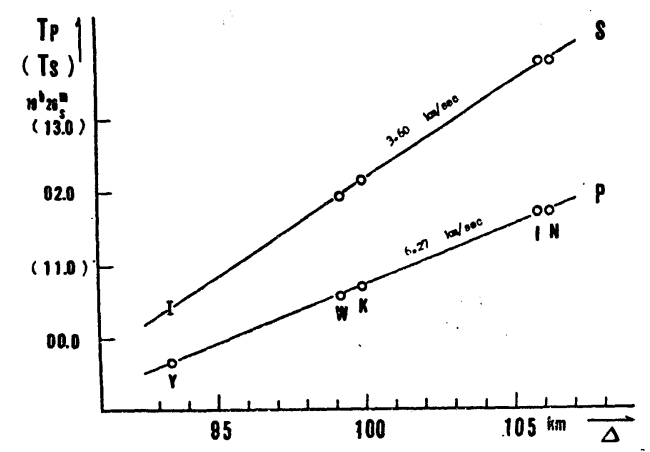

(b) No. 254

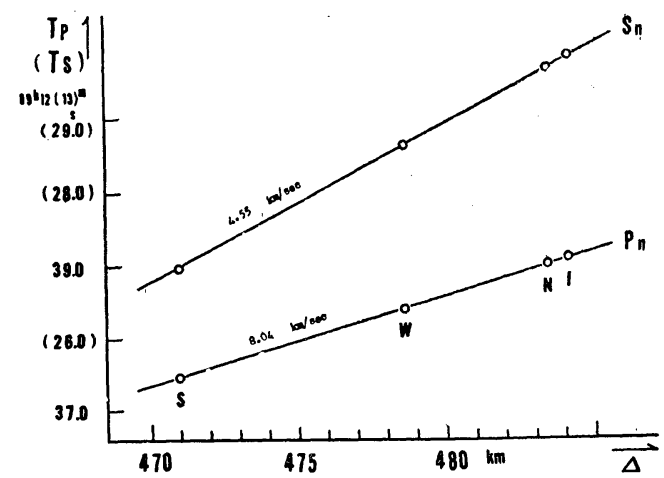

(d) No. 348

Fig. 4. Time-distance curves in four near earthquakes. 
観測点に括ける記録の時刻精度は，良好な場合で $1 / 50$ 秒，その他の場合でも $1 / 20$ 秒以内で ある．走時曲線はいずれる非常に良い精度で一直線で表わすことができる，これら近地地震波 の周期が局地地震の場合と大差ないことも併せ考えれば，この地方の各所の地殼構造には余り 著しい相違がないといえるであろう。

b） 3 点観測法 いまわれわれの観測網の span は $10 \mathrm{~km}$ 程度であるから，これに比 ベてかなり遠距離に起つた地震に対してはこの方法を適用して，地震波伝播の見掛速度と方向 を推定することができる，各観測点に和ける $P$ 波到着時刻の読取誤差を $1 / 20$ 秒とし，宮村の 方法7) に随つてこの方法に括ける誤差を求める と，方位については $3^{\circ} \sim 8^{\circ}$ ，見掛速度に関し ては 5〜14\% の誤差が考它られる。な叔，a) に述べた 4 個の地震にこの方法を適用した結果 は，a，b）両方法による差異が上の誤差の範囲 内にあることを示している。

両方法によつて求めた伝播速度和よび到来方 向は Table 1 と Fig. 5 に示した.

先に走時曲線を示した 4 個の地震の震源の深 さと震央距離を考慮すれば，No. 240,254, 371

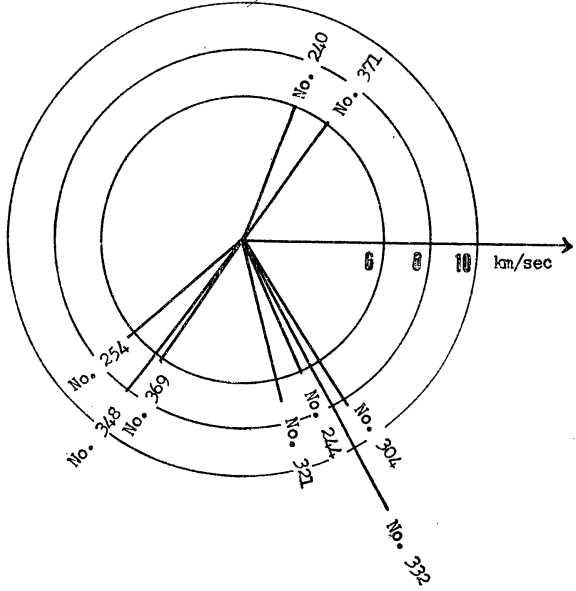

Fig. 5. Apparent velocity and direction of approach of initial $P$-wave.

Table 1. Observed results for near earthquakes.

\begin{tabular}{|c|c|c|c|c|c|c|c|c|c|}
\hline $\begin{array}{c}\text { Shock } \\
\text { No. }\end{array}$ & $V_{p}$ & $V_{s}$ & $V_{p} / V_{s}$ & $\Phi$ & A.M. & Stations & $H$ & $\lambda$ & $\varphi$ \\
\hline 240 & 6.00 & 3.40 & 1.77 & 70 & (1) & $\mathrm{I}, \mathrm{N}, \mathrm{W}, \mathrm{K}, \mathrm{Y}$ & 11 & $135^{\circ} 32^{\prime}$ & $35^{\circ} 01^{\prime}$ \\
\hline 254 & 6.27 & 3.60 & 1.74 & 221 & (1) & $\mathrm{Y}, \mathrm{W}, \mathrm{K}, \mathrm{N}, \mathrm{I}$ & 10 & $134^{\circ} 15^{\prime}$ & $33^{\circ} 45^{\prime}$ \\
\hline 348 & $\begin{array}{l}8.05 \\
6.10\end{array}$ & 4.55 & 1.77 & 233 & (1) & $\mathrm{S}, \mathrm{W}, \mathrm{I}, \mathrm{N}$ & $20 \sim 30$ & $132^{\circ} 12^{\prime}$ & $30^{\circ} 41^{\prime}$ \\
\hline 371 & 6.15 & 3.48 & 1.75 & 55 & (1) & $\mathrm{I}, \mathrm{N}, \mathrm{W}, \mathrm{S}$ & $10 \sim 15$ & $136^{\circ} 13^{\prime}$ & $35^{\circ} 25^{\prime}$ \\
\hline 244 & 6.13 & 3.53 & 1.74 & 296 & (2) & $\mathrm{N}, \mathrm{Y}, \mathrm{F}, \mathrm{Y}, \mathrm{W}$ & & & \\
\hline 304 & 8.14 & - & - & 304 & (2) & $\mathrm{N}, \mathrm{S}, \mathrm{W}$ & & & \\
\hline 321 & 7.08 & - & - & 285 & (2) & S, I, W & & & \\
\hline 332 & 12.95 & - & - & 300 & (2) & $\mathrm{N}, \mathrm{I}, \mathrm{W}$ & & & \\
\hline 369 & 6.14 & 3.46 & 1.77 & 234 & (2) & $\mathrm{W}, \mathrm{N}, \mathrm{I}$ & & & \\
\hline
\end{tabular}

$V_{p}, V_{s}$; the velocities of the $P$ - and $S$-waves, in $\mathrm{km} / \mathrm{sec}$.

$H$; the focal depth in $\mathrm{km}$.

$\Phi$; the direction of approach of initial wave, measured counter-clockwise from eastward at Wakanoura.

$\lambda, \varphi ;$ longitude and latitude indicating the location of epicentre.

A.M.; the analytical method, (1) time-distance graph method, (2) tripartite stations method. 
物よび No. 244, 369 で観測された約 $6.1 \mathrm{~km} / \mathrm{sec}$ の速度を持つ初動は第 2 層と第 3 層の境界 面直下を伝播してきた属折波，No. 348 の約 $8.0 \mathrm{~km} / \mathrm{sec}$ の速度の初動はモホロヴィナック不 連続間の直下を伝播した屈折波と考兄られ，随つてこれらの速度はそれぞれ第 3 層中和よび mantle 上部中のものとしてよいであろう。結局，局地地震和よび近地地震の観測から次のよ らな水平層構造が推定される。

$$
\begin{aligned}
& V_{p}=4.3 \mathrm{~km} / \mathrm{sec}, \quad V_{s}=2.4 \mathrm{~km} / \mathrm{sec}, \quad k=5.4 \mathrm{~km} / \mathrm{sec} \quad \text { (第 } 1 \text { 層） } \\
& V_{p}=5.5 \quad " V_{s}=3.2 \quad " \quad, \quad k=7.6 \quad " \text { (第 } 2 \text { 層) } \\
& V_{p}=6.1 ", \quad V_{s}=3.5 ", \quad k=8.2 " \text { （第 } 3 \text { 層） } \\
& V_{p}=8.0 ＂, \quad V_{s}=4.5 \quad " \quad, \quad k=10.3 ＂ \text { (第 } 4 \text { 層) }
\end{aligned}
$$

（2）顕著な位相について

上に述べた 9 個の近地地震の $P \sim S$ 間には幾つかの顕著な phase が見出される.これらの 位相の $P$ 波初動からの時間間隔を $P \sim S$ 時に対してプロットすれば Fig. 6 が得られる.

Fig. 6 の位相中， $P \sim S$ 時に関係なく一定の時間間隔を有する 2 つの phase が見出される. これらを $X_{\mathrm{I}}, X_{\mathrm{II}}$ と名付ければ，

$$
\begin{aligned}
& P \sim X_{\mathrm{I}}=0.91 \pm 0.03 \mathrm{sec} \text { (for } 9 \text { data in } 5 \text { shocks) } \\
& P \sim X_{\mathbb{I}}=2.32 \pm 0.05 \mathrm{sec} \text { (for } 11 \text { data in } 8 \text { shocks) }
\end{aligned}
$$

な拉，この他に，No. 348 の地震では $P \sim X_{\text {III }}=4.12 \pm 0.16 \mathrm{sec}$ なる 1 つの明瞭な phase が 存在する。

これらの phase の特徴は次のようである。

1）各地震，各観測点において観測される.

2）震央の距離，方向に無関係に観測される.

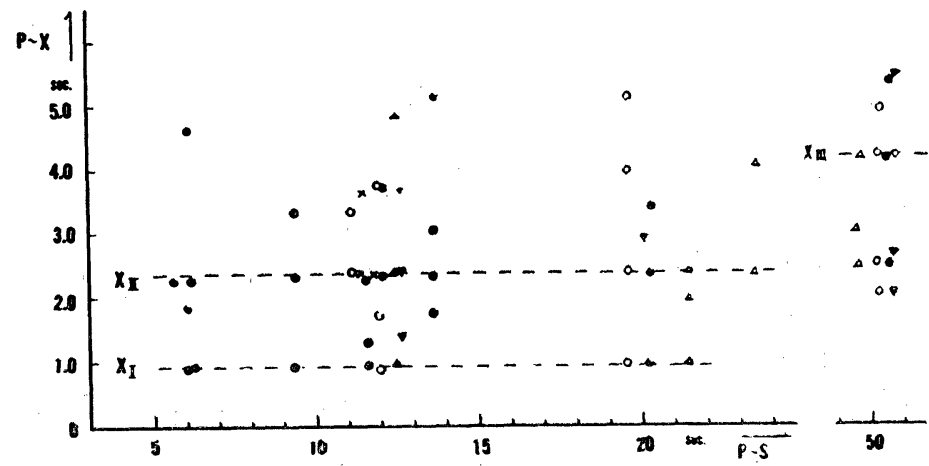

Fig. 6. Time intervals between the initial $P$-waves and the prominent phases mentioned. 
3）水平成分の記録に卓越し，上下成分には明瞭でない.

4）一定の polarization を示す．Fig. 7 はこの phase の入射時に和ける partle motion の locus の 1 例である. これから, 振動面は入射面に一致し, かつこの面内での振動方向は波 の入射方向に直角と看做せるから，この phase は $S V$-type と推定される.
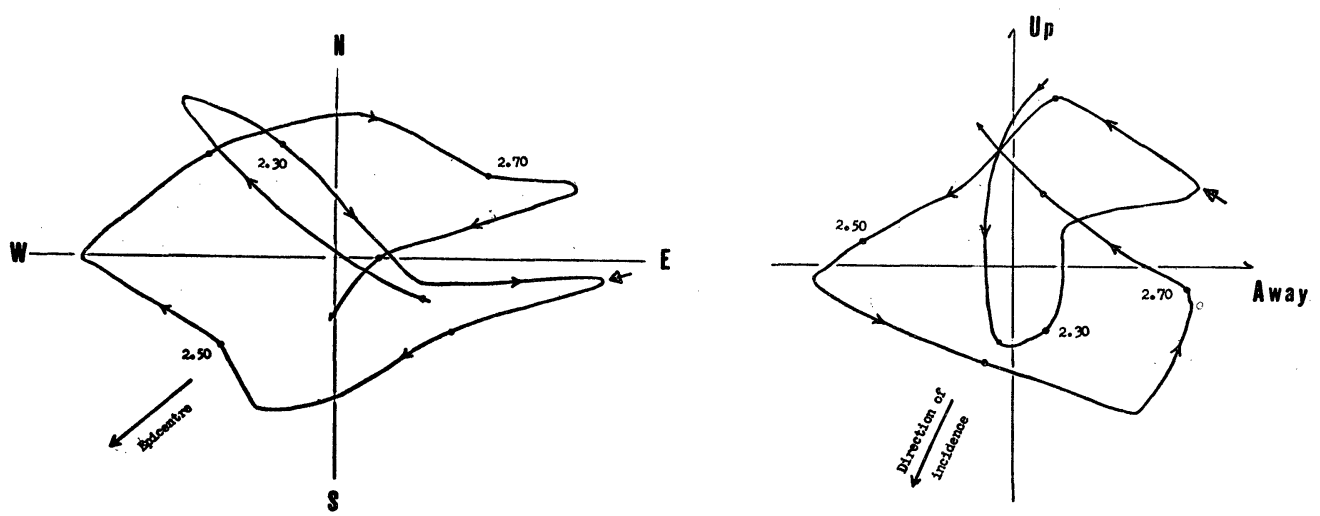

Fig. 7. Loci of particle motions of the phase $X_{\mathbb{I}}$.

このような性質から，ここに問題とした phase はいわゆる“変成波” $P S^{8) \sim 11)}$ と考孚て良い であろう。またこの場合の初動は前節に述べたような屈折 $P$ 波であるから，これらの変成波 はFig. 8 に示した “transformed refraction arrival”12),13) と考觉ることができる. 屈折波 の速度より， $X_{\mathrm{I}}, X_{\mathrm{II}}, X_{\mathrm{II}}$ はそれぞれ (1)'，(1)，(2) の場合に相当すると思われる.

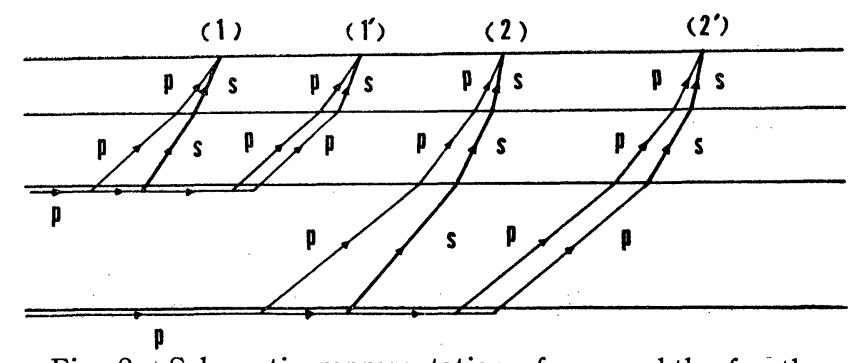

Fig. 8. Schematic representation of wave phths for the transformed waves.

5）次にこの推定を確めるために，それぞれの場合の変成波 $P S$ と屈折 $P$ 波の振幅の理論 的関係を求め, 観測值と比較した. 簡単のために, 途中の不続面による影響と, 振幅の距離に よる減衰を省略する。すず底面で屈折する際の $S V$ 波と $P$ 波の振幅比を求め, 次に地表面へ の入射角を用いて，地表面で記録されるべき両波の振幅比の概略值を計算した.

一般にある境界面へ $P$ 波が入射する際に生ずる屈折 $S V$ 波の振幅 $A_{S V^{\prime}}$ と屈折 $P$ 波の振 
幅 $A_{p}^{\prime}$ の比は次式で表わされる ${ }^{14)}$.

$$
\begin{array}{ll} 
& \frac{A_{s v^{\prime}}}{A_{p}^{\prime}}=\frac{\mu^{\prime}\left(b^{\prime 2}-1-2 a^{\prime} b\right)-\mu\left(b^{2}-1-2 a^{\prime} b\right)}{\mu^{\prime}\left[2 b^{\prime}+b\left(b^{\prime 2}-1\right)\right]+\mu\left[2 b+b^{\prime}\left(b^{2}-1\right)\right]} \\
\text { ここに, } \quad & a=\cot i_{p}, \quad b=\cot i_{s}, \quad a^{\prime}=\cot i_{p}^{\prime}, \quad b^{\prime}=\cot i_{s}^{\prime} \\
& V_{p} / \sin i_{p}=V_{s} / \sin i_{s}=V_{p}^{\prime} / \sin i_{p}{ }^{\prime}=V_{s}^{\prime} / \sin i_{s}^{\prime}
\end{array}
$$

$i_{p}, i_{s} ; i_{p^{\prime}}, i_{s}{ }^{\prime}$ はそれぞれ $P$ 波. $S V$ 波の入射角と屈折角, $V_{p}, V_{s} ; V_{p^{\prime}}, V_{s^{\prime}}$ は両方の媒質 中に扣ける両波の速度， $\mu$ ， 快両媒質の rigidityである. 各層の密度を第 1 層より順次 2.6, $2.8,3.0,3.2 \mathrm{gr} / \mathrm{cm}^{3}$ と仮定し，前節に求めた速度を用いて，各々の場合の，地表面に拈将る 両波の水平成分の振幅比を計算した結果は次のようになる。ただし $(1),(2)$ の場合は， $i_{p} \rightarrow 90^{\circ}$ とすると一定值に近付 $\left.{ }^{14)}, 15\right)$.

$\begin{array}{lllll}A_{S V^{\prime}} / A_{p^{\prime}} & 0.07 & 0.17 & 0.18 & 0.05 \\ \bar{A}_{S V(H)} / \bar{A}_{p(H)} & 0.08 & 0.20 & 0.29 & 0.08 \\ & (0.35 & 0.83 & 1.44 & 0.42)^{*}\end{array}$

振幅比の観測值は計算された值よりかなり大きい，この 1 つの原因としては，地表附近に更に 遅い速度の層があつて，波が殆んど直角に地表面へ入射するためと思われる．表面に $V_{p}=$ $1 \mathrm{~km} / \mathrm{sec}$ なる变成岩の風化した薄い層がある5 とすれば, 理論值は（）＊内の值になる．観測 值は大体この程度である.

（3）層の厚さの推定

变成波の走時については，いままでいくつかの式が求められているが8) 121，Fig. 8 に示し たような経路をとる変成波 ${ }^{13)}$ につては，比較的簡単な解が求められる，一般に，P波， $S$ 波 の速度が $V_{p j} V_{s j}$ なる厚さ $h_{j}$ の層 $(j=1,2, \cdots, n+1)$ より成る $n+1$ 層の水平成層構造 を考学ると，変成波 $P S_{n}$ と屈折 $P$ 波の走時差 $\delta t_{n}$ は次式で表わすことができる.

$$
\begin{aligned}
\delta t_{n} & =\sum_{j=1}^{n} h_{j}\left(\frac{\tan i_{p j}-\tan i_{s j}}{V_{p_{n+1}}}+\frac{1}{V_{s j} \cos i_{s j}}-\frac{1}{V_{p j} \cos i_{p j}}\right) \\
& =\sum_{j=1}^{n} h_{j}\left(\frac{\cos i_{s j}}{V_{s j}}-\frac{\cos i_{p j}}{V_{p j}}\right)
\end{aligned}
$$

ここに

$$
\sin i_{p j}=V_{p j} / V_{p_{n+1}}, \quad \sin i_{s j}=V_{s j} / V_{p_{n+1}}
$$

Fig. 8 のそれぞれの場合に和ける走時差は，先に求めた速度を用いれば， 


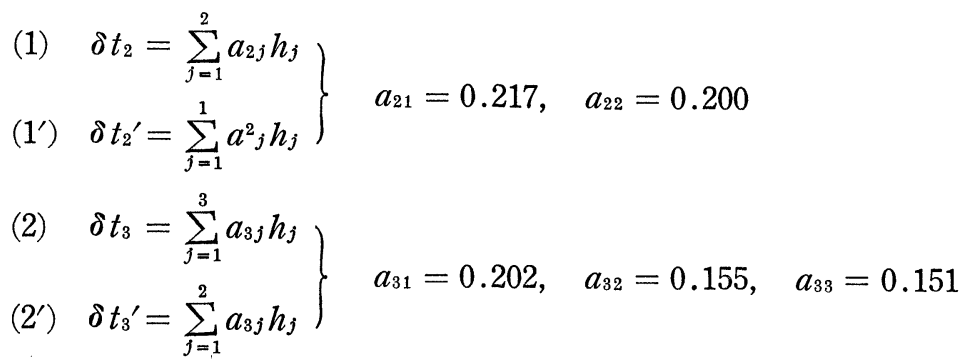

前に述べた通り, $\delta t_{2}=P \sim X_{\mathrm{II}}, \delta t_{2}{ }^{\prime}=P \sim X_{\mathrm{I}}, \delta t_{3}=P \sim X_{\mathrm{III}}$ と考学られるから, 各層の厚 さは次のように算出される。すなわち，

$$
\begin{aligned}
& h_{1}=4.2 \pm 0.2 \mathrm{~km}, \quad h_{2}=7.1 \pm 0.4 \mathrm{~km}, \quad h_{3}=14.6 \pm 1.2 \mathrm{~km} \\
& H=\sum_{j=1}^{3} h_{j}=25.9 \pm 1.8 \mathrm{~km}
\end{aligned}
$$

これらの誤差は phase の時間の誤差のみによるものであり，速度の精度を考慮すれば更に大 きくなるはずである.

$h_{1}$ は表層の厚さであつて, 局地地震観測から推定した值と良く一致する。 また $H$ はモホ不 連続面までの深さであり，近畿地方について従来考兄られていた值 ${ }^{16), 17), 18)}$ と大体一致する.

\section{$\S 5$, 和歌山地方の地殸構造と微小地震の震源分布}

以上述べてきた局地括よび近地地震の観測結果を綜合すれば，この地域の地殼構造は Fig. 9 に示したようなものと考兄られる.ただしこれは水平成層構造を仮定して求めたものである. この構造は，最近の爆破地震動観測から決定された近畿地方北部の構造 ${ }^{19)}$ と大きい矛盾はな

\begin{tabular}{|c|c|c|c|c|}
\hline & & $V_{p}$ & $V_{s}$ & \\
\hline \multirow{3}{*}{$26 \mathrm{~km}$} & $4 \stackrel{\uparrow}{\downarrow}$ & $4.3 \mathrm{~km} / \mathrm{sec}$ & $2.4 \mathrm{~km} / \mathrm{sec}$ & sedimentary layer \\
\hline & $\underset{\downarrow}{7 \mathrm{~km}}$ & $5.5 \mathrm{~km} / \mathrm{sec}$ & $3.2 \mathrm{~km} / \mathrm{sec}$ & granitic layer \\
\hline & $15 \stackrel{\uparrow}{\mathrm{km}}$ & $6.1 \mathrm{~km} / \mathrm{sec}$ & $3.5 \mathrm{~km} / \mathrm{sec}$ & \multirow{2}{*}{$\begin{array}{l}\text { basaltic layer } \\
\text { Mohorovičcić discontinuity } \\
\text { ultrabasic layer }\end{array}$} \\
\hline & & $8.0 \mathrm{~km} / \mathrm{sec}$ & $4.5 \mathrm{~km} / \mathrm{sec}$ & \\
\hline
\end{tabular}
い.

Fig. 9. Crustal structure in Wakayama region.

次に地殼構造と, この地方に発生する微小地震の空間分布との関係を調べるために, Fig. 10 に震源位置をプロットした. この図は南北の断面を示し，深さと水平方向の縮率は同じであ る. 図中 ○印はわれわれの観測によつて定められた $10^{13}$ エルグ以下のエネルギーを持つ微小 地震の震源であり，凤印は 1952 1954 年の東大地震研究所の観測 ${ }^{3)}$ のち， 4 観測点以上の 


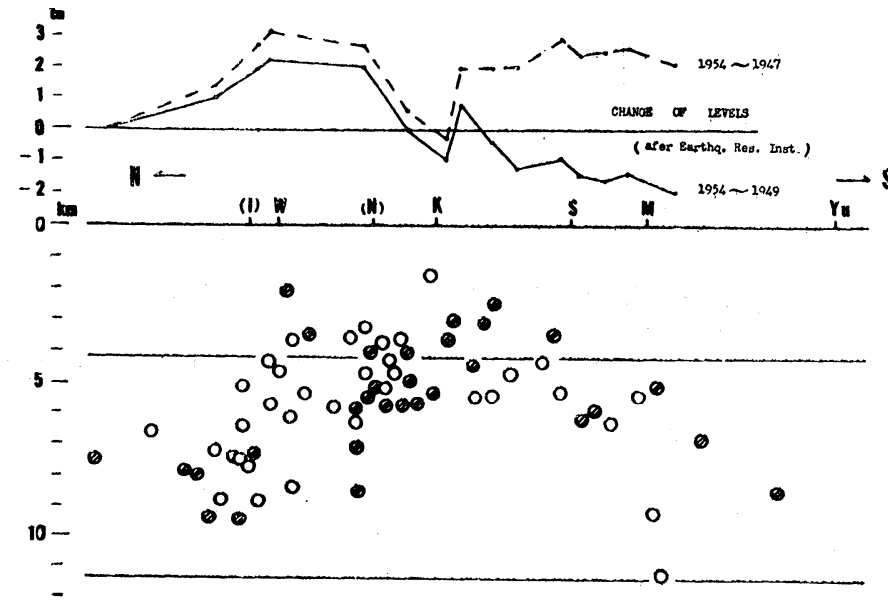

Fig. 10. Spatial distribution of foci of local shocks and the change in ground levels.

観測值から決定された，前者に比べてかなり大きい地震の震源を示す。これらは，地震の大き さにあまり関係なく殆んど同じょうな分布状態を示している。また，これらの地震が和歌山地 方北部では, 全部 granitic layer より上部に発生し, しかも一部が sedimentary layer に起 つていることは，関東地方などに括ける局地地震の分布状態》，20) と著しい対照をなしている.

これらの震源位置は，地殼上部の構造を一様なるのと仮定して求めたものである．先に推定 したような水平成層構造を uniform medium として震源を決定した時に生ずる誤差は，計算 によれば， $P$ 波の到着時または $P \sim S$ 時のいずれを用いても，震源の深さにして $1 \mathrm{~km}$ に達 せず，震央位置には殆んど影響がない。至震央が観測網の中央にある場合より，端にある時 の方が，震源はやや浅く算出されることが分つた，いずれにしても，震源の分布状態の大きい 傾向は変らない。

この震源分布が海南附近で最も浅く, 南北へ行くに随つて漸次深くなることは注目すべき傾 向である. Fig. 10 には震源分布とともに，東大地震研究所が行なつた精密水準測量の結果 ${ }^{1}$ を示した. この結果から見た地殼变動の状況と, この地方の微小地震の震源分布状態との間に は何らかの関係があるように思われる。

\section{§6. 結 語}

局地地震拉よび近地地震の観測結果から，和歌山地方の地殼構造を推定した。水平成層構造 を仮定して得られた結果は Fig. 9 に示された通りである.この地方の地殼の厚さは約 $26 \mathrm{~km}$ と考觉られる。またこの地域の北部では，微小地震は殆んどすべて granitic layerにより上部 に発生していることが明らかになつた. 
終りに, いろいろ適切な助言を戴いた西村英一博士，佐々憲三博士，括よび室内実験の御指 導を戴いた松島昭吾氏に御礼申乙上げる. また本観測に御協力下さつた住友則彦, 橋爪道郎, 奥西一夫，西勝也，石束昌治特よび森勝也の諸氏に感謝の意を表したい.

\section{参 考 文 献}

1) 東京大学地震研究所： 和歌山頻発地震研究概要 (1955).

2) T. Mikumo: Mem. Coll. Sci., Kyoto Univ., A 28 (1956), 161.

3) 宮村摂三： Bull. Earthq. Res. Inst., 37 (1959), 609; 38 (1960), 71.

4) T. Mikumo: (印刷中).

5) 吉沢 徹: 物理採鉱技術協会講演 (1955 年 4 月).

6) A. Kubotera: Journ. Phys. Earth, 1 (1954), 33.

7) 宮村掑三，辻浦 賢： Bull. Earthq. Res. Inst., 37 (1959), 370.

8) T. Matuzawa, K. Hasegawa and S. Haeno: Bull. Earthq. Res. Inst., 4 (1928), 85.

9) T. Matuzawa, R. Yamada and T. Suzuki: Bull. Earthq. Res. Inst., 7 (1929), 241.

10) Z. Kinoshita: Bull. Earthq. Res. Inst., 15 (1937), 965.

11） 飯田汲事, 青木治三：地震 12 (1959), 75.

12) D.N. Rustanovich: Izv. Akad. Nauk, SSSR, ser. geofiz. (1957), 10.

13) S. S. Andreev: Izv. Akad. Nauk, SSSR, ser. geofiz. (1957), 21.

14) M. Ewing, W. S. Jardetzky and F. Press: Elastic waves in layered media, 83 89.

15) B. Gutenberg: Bull. Seism. Soc. Amer., 34 (1944), 85.

16) Y. Kishimoto: Mem. Coll. Sci., Kyoto Univ., A 27 (1954), 243.

17) .玉城逸夫：地震 7 (1954), 1.

18) A. Kamitsuki: Mem. Coll. Sci., Kyoto Univ., A 28 (1956), 143.

19) 爆破地震動研究グループ: 地震学会講演 (1960 年 5 月).

20) T. Asada: Journ. Phys. Earth., 5 (1957), 83. 